transcultural psychiatry. These are facts which have a bearing on the nature and management of the disease and it is to be deplored that Drs Sashidharan and Lipsedge have politicised this information in their recent letter (Journal, April 1986, 148, 484).

Scientific truth is a bastion of strength in a world which is confused by misinterpretative and exploitative statements. It is particularly distressing in this regard that Drs Sashidharan and Lipsedge have cast aspersions on the scientific integrity of the Journal's Editor and assessors by stating that an article "with politically loaded definitions of little scientific import" was published.

A. F. Teggin
O. Ben-Arie
L.S. Gillis

\section{Reference}

World Health Organization (1974) Report of the International Pilot Study of Schizophrenia. Vol. 1. Geneva: WHO.

Depression in Schizophrenia: Prevalence and Treatment

Sir: With regard to the paper by Elk et al (Journal, August 1986, 149, 228-229) although the point has been made previously elsewhere it seemingly needs to be made again.

The "Population Registration Act, 1950 (as amended)" does not define homogeneous "ethnic groups" but groups together "whites, blacks and coloureds" whose members may have very different origins, languages, cultures and social circumstance from co-members of the same so-called groups. By accepting this paper in its published form I feel that the Journal has been done a disservice and that another layer of veneer has been placed on the pseudo-scientific basis of apartheid.

\section{St Cadoc's Hospital,}

JAMEs Graham

\title{
Control of Auditory Hallucinations with Earplugs
}

Sir: I read with interest Dr Birchwoods article (Journal, July 1986, 149, 104-107). I can recall very clearly two schizophrenic patients who wore earplugs to shut out the 'voices'. The first one was a male in his forties that I saw at Castle Peak Hospital in Hong Kong in 1970 and the second was a male patient in his sixties at Springfield Hospital in London in 1977. As I recall, the first patient wore earplugs in both ears while the second only in his left. Both of them told me that the earplug helped to block out the voices. At that time I said to myself "this is just part of their thought disorder" and paid no further attention to it. Another lesson that we should listen more to what our patients say.

\section{University of Pittsburgh}

L. K. George Hsu

Western Psychiatric Institute and Clinic

3811 O'Hara Street,

Pittsburgh, Pennsylvania

\section{A HUNDRED YEARS AGO}

\section{A Lunatic Imprisoned Again}

Why do the City Fathers persist in imprisoning Herbert Percy Freund, seeing that he is certainly "a person of unsound mind"? Is it that they deem it less costly to keep him one-third of his time in gaol than to maintain him altogether in an asylum? The question of humanity ought to have some little weight as against the question of economy. Besides which, it may one day happen that this lunatic will no longer be contented with declaiming against St Paul's Cathedral as "that house of idols over there". He may turn iconoclast on his own account; or, instead of predicting the downfall of the City, he may do something towards the fulfilment of his prophecies. The policy of the City magistrates is neither sound nor safe, and it is certainly anything but benevolent.

\section{Reference}

Lancet (February 20, 1886) Pp 368.

Researched by Henry Rollin, Emeritus Consultant Psychiatrist, Horton Hospital, Surrey. 